\title{
TREATMENT OF UNSTABLE FRACTURES OF THE DISTAL RADIUS BY EXTERNAL FIXATION
}

\author{
PAUL A. VAUGHAN, SPENSER M. LUI, IAN J. HARRINGTON, GIANNI L. MAISTRELLI
}

\author{
From the Toronto East General and Orthopaedic Hospital, and the University of Toronto
}

\begin{abstract}
The Roger Anderson external fixator was used in the treatment of unstable fractures of the distal radius in 52 patients, and the results evaluated after a follow-up averaging 58 months.

The indications for its use were failure to maintain adequate closed reduction using plaster, and instability of the fracture as determined by the initial radiographs. Our radiological criteria for instability included dorsal angulation of more than $\mathbf{2 0}^{\circ}$, fractures involving the joint, radial shortening of more than $10 \mathrm{~mm}$, and severe dorsal comminution.

Using the Lucas modification of the Sarmiento demerit point-rating system, we found that $\mathbf{4 6}$ patients $(89 \%)$ had good or excellent results and six $(11 \%)$ were classified as fair. There were no poor results. Seven patients $(14 \%)$ developed complications. None of these affected the long-term results except in one elderly woman where the pins loosened and had to be removed.
\end{abstract}

Although the optimum treatment of Colles' fractures remains controversial, functionally good results can be expected in most patients treated by closed reduction and plaster immobilisation. There are some fractures of the distal end of the radius, however, where results are consistently poor. In particular, badly comminuted and/or intra-articular fractures present specific problems in management (Gartland and Werley 1951; Bacorn and Kurtzke 1953; Frykman 1967). It is generally agreed that although reduction of these fractures may be easy to achieve, it is extremely difficult to maintain. Shortening of the radius and reversion to the original dinner-fork deformity after a few days or weeks is a frequent complication. The problem is related to instability of the fracture due to comminution of the dorsal cortex of the radius and intra-articular components.

A variety of methods have been devised to avoid loss of reduction, including pinning the distal fragment percutaneously (DePalma 1952; Dowling and Sawyer 1961; Munson and Gainor 1981), immobilising the wrist and forearm in supination (Sarmiento et al. 1975), above-elbow casts, fixing the fracture fragments with

P. A. Vaughan, MD, FRCS(C), Clinical Research Fellow, University of Toronto

S. M. Lui, MD, FRCS(C), Clinical Research Fellow, University of Toronto

G. L. Maistrelli, MD, FRCS(C), Clinical Research Fellow, University of Toronto, Toronto, Ontario, Canada M5S IAS

I. J. Harrington, BASc(Eng), MD, FRCS(C), MS(Tor), MSc(Strath), Assistant Professor of Orthopaedic Surgery, University of Toronto

Toronto East General and Orthopaedic Hospital, 825 Coxwell Avenue, Toronto, Ontario, Canada M4C 3E7.

Requests for reprints should be sent to Dr I. J. Harrington.

(C) 1985 British Editorial Society of Bone and Joint Surgery $0301-620 \mathrm{X} / 85 / 3084 \$ 2.00$ pins incorporated in a plaster cast (Bohler 1932; MacFarlane and Thomas 1937; Scheck 1962; Brady 1963; Cole and Obletz 1966; Marsh and Teal 1972; Green 1975), using an external fixator (Anderson and O'Neil 1944; Conney, Linscheid and Dobyns 1979; Grana and Kopta 1979; Forgon and Mammel 1981), and the use of longitudinal pins (Rush and Rush 1949; Lucas and Sachtjen 1981). The basic principle in many of these methods is to provide fixed traction which prevents shortening of the radius. All have claimed success, in varying degree.

Anderson devised a technique whereby traction was achieved by inserting a Kirschner wire through the distal third of the shaft of either the first or second metacarpal and two wires proximal to the fracture site (Anderson and O'Neil 1944). Distraction was maintained by connecting the distal and proximal wires to an outrigger. At the Toronto East General and Orthopaedic Hospital a modification of this technique has been employed for the treatment of unstable Colles' fractures, and the followup results of 52 patients from 1968 to 1983 have been assessed.

\section{PATIENTS AND METHODS}

Between March 1968 and July 1983, 59 patients with unstable fractures of the distal radius were treated with the Roger Anderson external fixator at the Toronto East General and Orthopaedic Hospital. This represents less than $10 \%$ of all the Colles' fractures treated at our hospital.

The indications for using the Roger Anderson external fixator were failure to maintain an adequate closed reduction with plaster-cast immobilisation; and instability of the fracture as determined by the initial antero- 
posterior and lateral radiographs, indicating that plastercast immobilisation would probably not maintain the reduction.

Our criteria for instability on the initial radiographs included dorsal angulation of more than $20^{\circ}$; fractures which involved the wrist joint; radial shortening of more than $10 \mathrm{~mm}$; and severe dorsal comminution of the fracture site.

Of the 59 patients treated, follow-up was possible in $52(88 \%)$. The follow-up ranged from 6 months to 8 years with an average of 58 months. There were 14 men and 38 women. The average age was 52 years (60 years for women and 37 for men).

Thirty patients had immediate fixation (within one day of the fracture) and 22 had delayed fixation with the Roger Anderson external fixator; the average delay was 11 days (range 3 to 17 days).

The mechanism of injury in the older women was almost always a fall on the outstretched hand. In the younger men the injury was usually more violent-motor vehicle accidents (4) and falls at work from a height of over four feet (10).

Thirteen patients $(25 \%)$ had associated injuries, including two fractures of the clavicle, two fractures of the metacarpals in the contralateral limb, two undisplaced scaphoid fractures in the contralateral limb, four fractures of the surgical neck of the humerus in the ipsilateral limb, a fracture of a rib, an undisplaced radial head fracture, and a tibial fracture. In eight patients $(15 \%)$ the fracture of the radius was compound.

Analysis of the original radiographs showed that there were four Smith's fractures (volar displacement of the distal fragment), one Barton's fracture (proximal displacement of the carpus accompanied by a fragment of the radius, including part of the articular surface) and 47 Colles' fractures (dorsal displacement of the distal fragment). All the fractures showed a moderate to severe amount of comminution.

Using Frykman's (1967) classification (Table I), $40 \%$ of the fractures were Type VIII, $40 \%$ were Type VII, and the remaining $20 \%$ were distributed equally between Types IV, V, and VI.

The initial mean dorsal angulation was 27 (range 10 to 53 ), the initial mean shortening of the radius was $10 \mathrm{~mm}$ (range 3 to $20 \mathrm{~mm}$ ), and the initial mean radial angulation was 6 (range -16 to $+24^{\circ}$ ). In the normal wrist there is 10 of volar and 22 of radial angulation (van der Linden and Ericson 1981).

Technique (Figs 1 and 2). The external fixator is applied in the operating room under sterile conditions. We use general anaesthesia for most patients, but we have also used regional lidocaine block or axillary block with good results. The pins are of $2.3 \mathrm{~mm}$ diameter. Anderson's technique has been slightly modified in that two pins are inserted at $90^{\circ}$ to one another and at $45^{\circ}$ to the second metacarpal shaft. This is done only after flexing the metacarpophalangeal joints to 90 to prevent tethering
Table I. Frykman`s (1967) classification of fractures

\begin{tabular}{ll}
\hline Type & Fracture \\
\hline I & Extra-articular, no fracture of ulna \\
II & Extra-articular, fracture of ulna \\
III & Intra-articular radiocarpal, no fracture of ulna \\
IV & Intra-articular radiocarpal, fracture of ulna \\
V & Intra-articular radio-ulnar, no fracture of ulna \\
VI & Intra-articular radio-ulnar, fracture of ulna \\
VII & $\begin{array}{l}\text { Intra-articular radiocarpal and radio-ulnar, no fracture of } \\
\text { ulna }\end{array}$ \\
VIII & Intra-articular radiocarpal and radio-ulnar, fracture of ulna \\
\hline
\end{tabular}

of the intrinsic muscles, which may occur if the fingers are extended at the time of pin insertion. Pins are then inserted in a similar fashion proximally (in the distal third of the radius). All four pins are connected to an outrigger after reduction of the fracture. The clamps holding the interconnecting rods are then tightened and sterile dressings are applied to the pin sites.

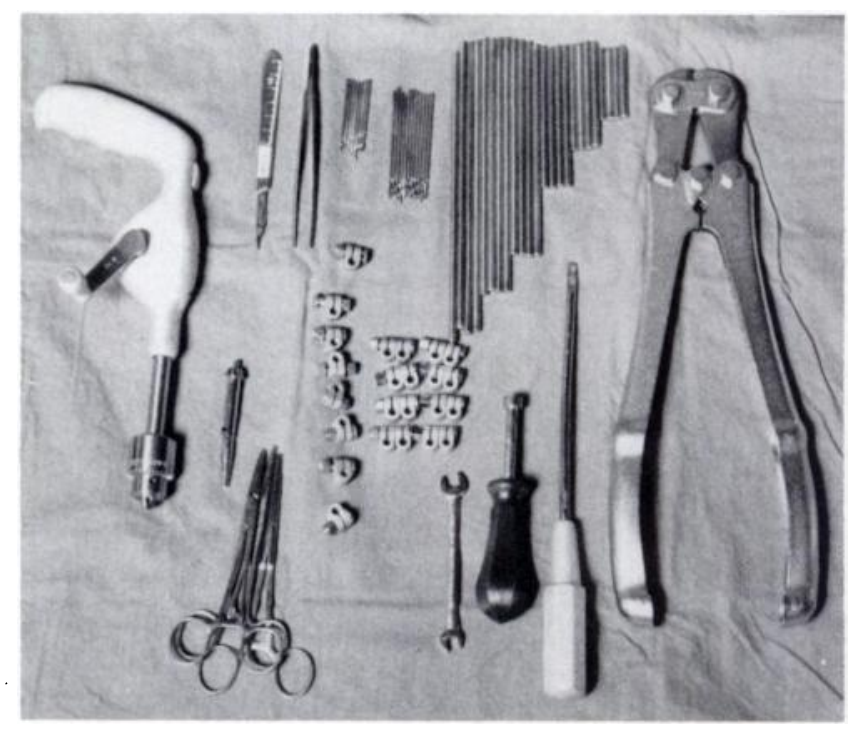

Fig. 1

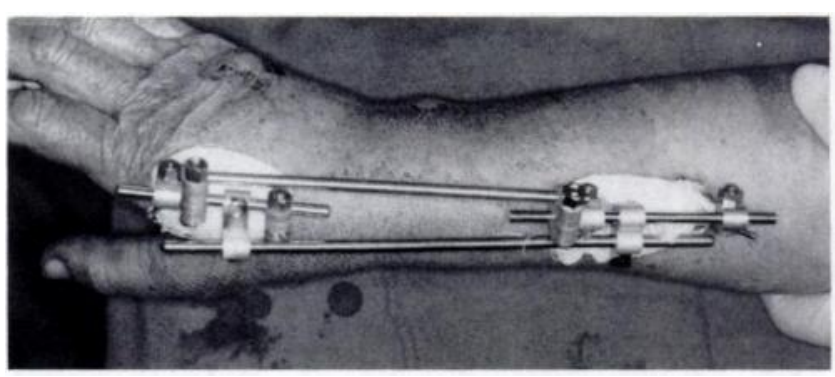

Fig. 2

Figure 1-Equipment used for application of the external fixator: hand drill, Crowe pins, connecting rods, clamps, wrench, and screwdriver. Figure 2-External fixator applied to the wrist with two pins in the second metacarpal connected to two pins in the radius via two connecting rods. 
Postoperatively the hand is elevated, the neurovascular status is closely monitored, and the patient is instructed in exercises for the fingers, elbow and shoulder.

The average stay in hospital after operation was four days (range 1 to 14 days). The apparatus was left on for approximately eight weeks.

\section{RESULTS}

Fifty-two patients with an average follow-up of 58 months were evaluated with the Lucas modification of the Sarmiento demerit point-rating system (Table II; Sarmiento et al. 1975; Lucas and Sachtjen 1981). Using this scale, 15 patients $(29 \%)$ were found to have excellent results, $31(60 \%)$ good results, and six patients $(11 \%)$ were classified as fair. There were no poor results.

Subjectively, 44 patients $(85 \%)$ were fully satisfied, three patients $(6 \%)$ were partially satisfied, and five patients $(9 \%)$ were unsatisfied with their final result. Of the three patients who were only partially satisfied, one had occasional wrist pain in damp weather or with overexertion, one had pain at the site of insertion of the pin in the second metacarpal, and one had pain over the distal radio-ulnar joint. No patient had a significant decrease in functional capacity. All five unsatisfied patients had severe almost continuous pain in the wrist; but their rating in the non-subjective categories raised them above the "poor" results. All patients who were working returned to their usual work.
Table II. Demerit point-rating system*

\begin{tabular}{|c|c|}
\hline Results & Demerit points \\
\hline $\begin{array}{l}\text { Residual deformity } \\
\text { Prominent ulnar styloid } \\
\text { Residual dorsal tilt } \\
\text { Radial deviation }\end{array}$ & $\begin{array}{l}1 \\
2 \\
2-3\end{array}$ \\
\hline $\begin{array}{l}\text { Subjective } \\
\text { Excellent (no pain) } \\
\text { Good (rare pain) } \\
\text { Fair (occasional pain) } \\
\text { Poor (frequent or constant pain) }\end{array}$ & $\begin{array}{l}0 \\
2 \\
4 \\
6\end{array}$ \\
\hline $\begin{array}{l}\text { Objective } \\
\text { Loss of dorsiflexion } \\
\text { Loss of ulnar deviation } \\
\text { Loss of supination } \\
\text { Loss of volar flexion } \\
\text { Loss of radial deviation } \\
\text { Pain in distal radio-ulnar joint } \\
\text { Loss of pronation }\end{array}$ & $\begin{array}{l}5 \\
3 \\
2 \\
1 \\
1 \\
1 \\
2\end{array}$ \\
\hline $\begin{array}{l}\text { Complications } \\
\text { Minimal arthritis } \\
\text { Minimal arthritis with pain } \\
\text { Moderate arthritis } \\
\text { Moderate arthritis with pain } \\
\text { Severe arthritis } \\
\text { Severe arthritis with pain } \\
\text { Median nerve impairment } \\
\text { Finger stifness } \\
\text { Reflex sympathetic dystrophy }\end{array}$ & $\begin{array}{l}1 \\
3 \\
2 \\
4 \\
3 \\
5 \\
1-6 \\
1-6 \\
1-6\end{array}$ \\
\hline $\begin{array}{l}\text { End-result } \\
\text { Excellent } \\
\text { Good } \\
\text { Fair } \\
\text { Poor }\end{array}$ & $\begin{array}{l}0-2 \\
3-6 \\
7-18 \\
19 \text { and more }\end{array}$ \\
\hline
\end{tabular}

* From Sarmiento et al. (1975), modified by Lucas and Sachtjen (1981)

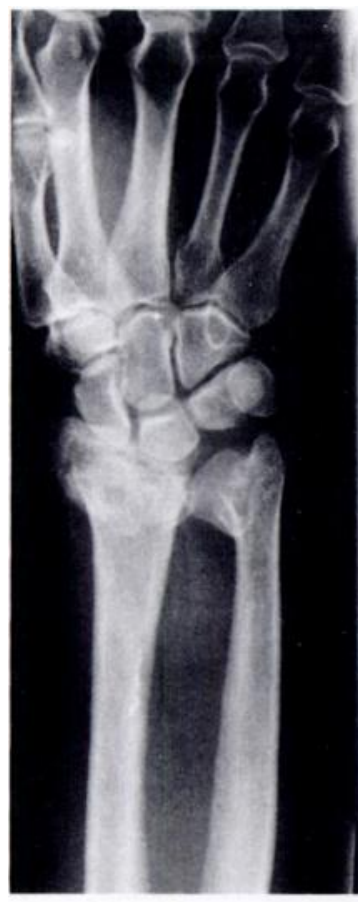

Fig. 3

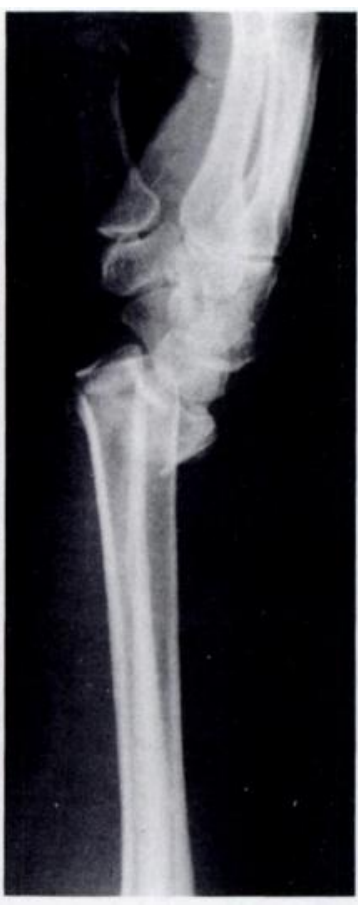

Fig. 4
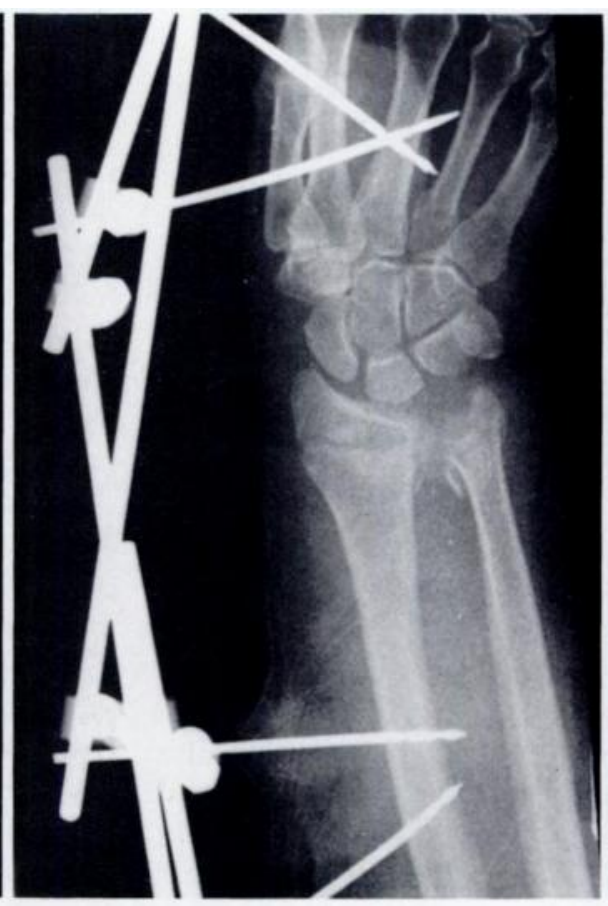

Fig. 5

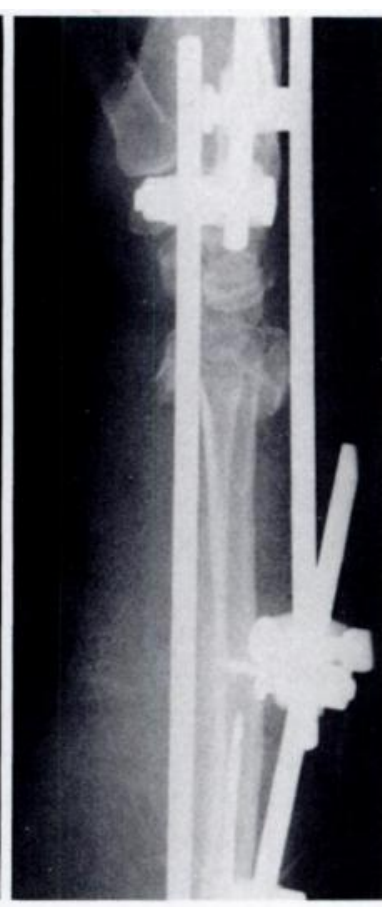

Fig. 6

Figures 3 and 4-Initial anteroposterior and lateral radiographs of an unstable Colles' fracture (Frykman VIII) in a 72-year-old woman; this injury was caused by a fall at home. Figures 5 and 6 - Radiographs after reduction, with the fracture held securely by the Roger Anderson device. 


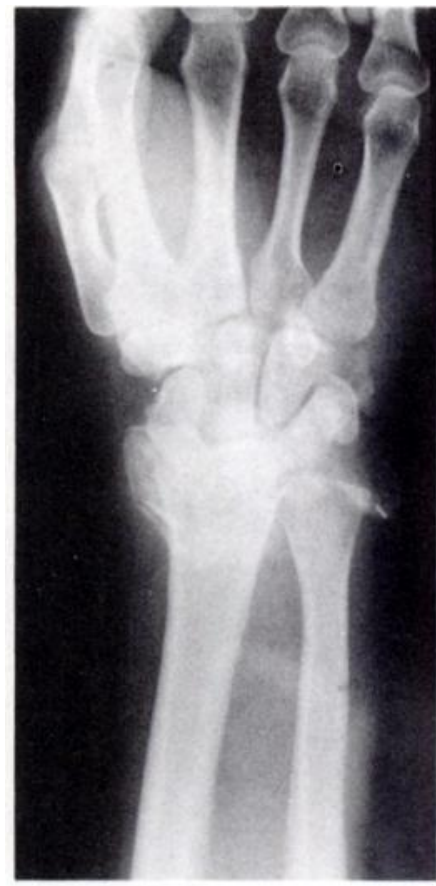

Fig. 7

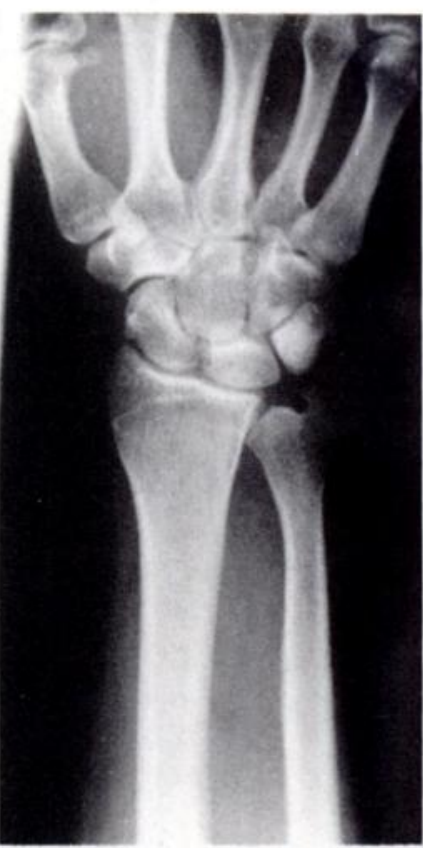

Fig. 11

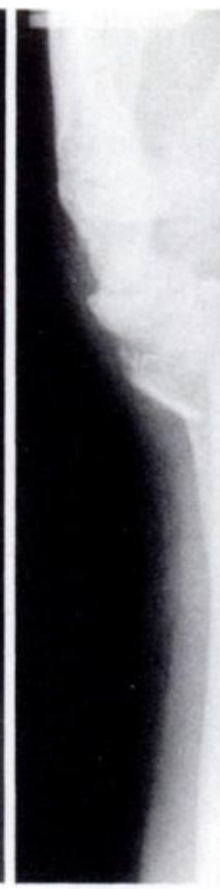

Fig. 8

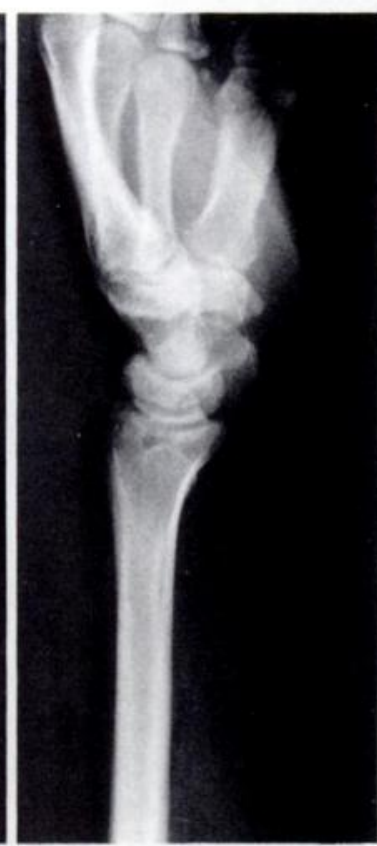

Fig. 12

Wrist movements were measured and as compared with the uninjured side (in brackets) showed an average dorsiflexion of $54(64)$, palmarflexion $48^{\circ}\left(60^{\circ}\right)$, radial deviation $19(22)$, ulnar deviation $32^{\circ}\left(40^{\circ}\right)$, pronation $80(85)$, and supination $73^{\prime \prime}\left(80^{\prime \prime}\right)$. There was restriction of flexion of the metacarpophalangeal and proximal interphalangeal joints of the index and middle fingers in seven patients and limited extension of the same fingers in two patients.

We were able to obtain serial radiographs of 34 patients $(65 \%)$ and found that, after reduction, 16

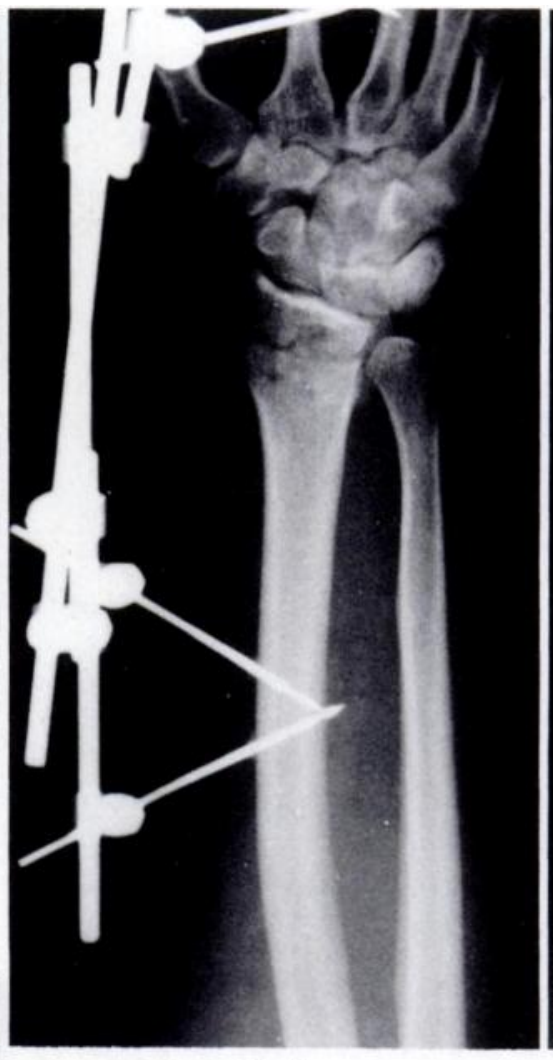

Fig. 9

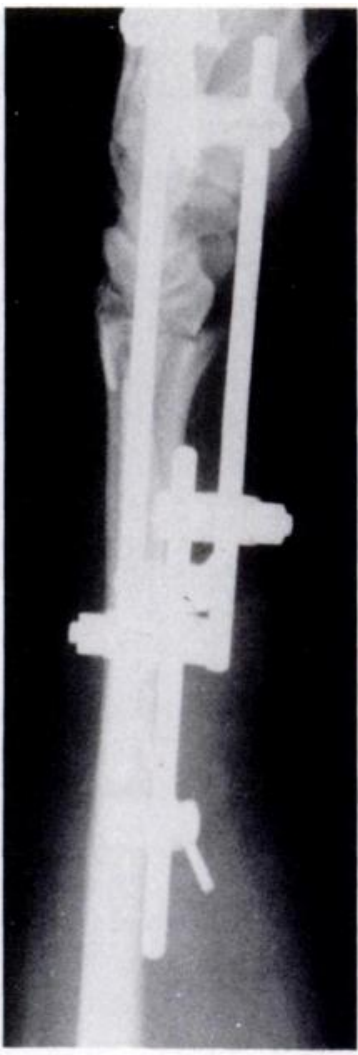

Fig. 10
Figures 7 and 8- Initial anteroposterior and lateral radiographs of an unstable Colles' fracture with articular involvement in a 29 -year-old man; the injury was caused by a 12 -foot fall at work. Figures 9 and 10 -Anteroposterior and lateral views after reduction, with the Roger Anderson external fixator applied. Figures 11 and $12-$ Follow-up radiographs eight weeks after removal of the fixator device.

patients $(47 \%)$ had a Grade I fracture (no deformity, no dorsal angulation beyond neutral and shortening of $3 \mathrm{~mm}$ or less). Sixteen patients $(47 \%)$ had a Grade II fracture with slight deformity or none (dorsal angulation of $1^{\circ}$ to $11^{\circ}$ and shortening of 6 to $12 \mathrm{~mm}$ ), one patient had a Grade III with mild to moderate deformity (dorsal angulation of $11^{\circ}$ to $15^{\circ}$ and shortening of 6 to $12 \mathrm{~mm}$ ), and one patient had a severe deformity (more than $15^{\circ}$ of dorsal angulation or more than $12 \mathrm{~mm}$ of shortening). The final volar angulation averaged $2^{\circ}$ (range $12^{\circ}$ volar to 28 dorsal); the normal volar tilt is $10^{\circ}$ but these patients initially had an average of $27^{\circ}$ dorsal angulation. The final radial angulation averaged $20.5^{\circ}$ (range $0^{\circ}$ to $30^{\circ}$ ); the normal radial angulation is $22^{\circ}$ but these patients initially had an average of $6^{\circ}$. The average final amount of shortening was $1.8 \mathrm{~mm}$ (range from 0 to $10 \mathrm{~mm}$ ) compared with an average initial shortening of $10 \mathrm{~mm}$ (Figs 3 to 6 , and 7 to 12 ).

Complications. Seven patients $(14 \%)$ developed complications. Two patients experienced irritation of the dorsal sensory branch of the radial nerve; in one symptoms sub- 
sided spontaneously, but the other continues to have paraesthesia over the dorsum of the thumb. One patient had a secondary undisplaced fracture of the radius through the site of a radial pin one year after operation; this fracture healed uneventfully. One patient developed a superficial pin-track infection which responded to antibiotics; the Roger Anderson device did not need to be removed. In two patients a pin broke in the medullary canal of the radius during insertion but there have been no problems from this as yet. One 82-year-old woman, who was very osteoporotic, suffered loosening of her pins and at two weeks the Roger Anderson device had to be removed; she was treated by immobilisation in a plaster cast but was left with $10 \mathrm{~mm}$ of shortening of the distal radius and significant deformity of the wrist. None of the patients developed median nerve compression or reflex dystrophy.

\section{DISCUSSION}

Unstable comminuted fractures of the distal radius present a major problem in terms of stability and methods of immobilisation. The overall results of treatment by our modification of Roger Anderson fixation have been good in nearly $90 \%$ of cases. Although the Roger Anderson apparatus was designed to allow early movement of the elbow, forearm and fingers, restricted movement of the wrist and fingers may occur; the restriction of finger movement is perhaps the more disabling and occurred in seven patients $(13 \%)$.

The cause of this restricted movement is not obvious, but we believe it may be due to two factors. If, when the metacarpal pins are inserted, the fingers are extended, tethering of the intrinsic muscles may occur, thereby limiting finger flexion; secondly, attempts to secure better fixation by inserting the pins across the second web space into the shaft of the third metacarpal may tether and cause subsequent scarring of the dorsal interossei, restricting movement of the index and middle fingers-insertion of the distal pins should probably be confined to the cortices of the second metacarpal. It should be noted, however, that restriction of movement involving primarily the index and middle fingers has been observed as a complication of Colles' fractures treated by casting techniques, so that the case for incriminating the pins is by no means complete.

We found an excellent cosmetic result in all but two of our patients. In one of these the external fixator had to be removed because of pin loosening in osteoporotic bone at two weeks.

Although wrist movement was not always restored to normal, we found that, compared with the uninjured wrist, our patients regained between $80 \%$ and $90 \%$ of movement. This good functional result reflects the maintenance of the original anatomical reduction afforded by the external fixator. We agree with Conney et al. (1979) that unstable Colles' fractures require firm fixation to prevent shortening and deformity.
It has been suggested in the literature (Grana and Kopta 1979) that the external fixator is only warranted in younger patients with strong bony cortices. Our experience does not substantiate this, as we found only one instance of pin loosening out of 25 patients over the age of sixty.

Finally, we would recommend that the Roger Anderson external fixator be left in for eight weeks rather than four to six weeks as some advocate, because of the severe amount of comminution found in these patients. In our series, $80 \%$ of the fractures were classified as Frykman's Types VII and VIII, indicating instability.

\section{REFERENCES}

Anderson R, O'Neil G. Comminuted fractures of the distal end of the radius. Surg Gynecol Obstet 1944;78:434-40.

Bacorn RW, Kurtzke JF. Colles' fracture: a study of two thousand cases from the New York State Workmen's Compensation Board J Bone Joint Surg $[\mathrm{Am}]$ 1953;35-A:643-58.

Bohler L. The treatment of fractures. 3rd ed. New York: Grune \& Stratton, 1932;90-6.

Brady LP. Double pin fixation of severely comminuted fractures of the distal radius and ulna. South Med J 1963;56:307-11.

Cole JM, Obletz BE. Comminuted fractures of the distal end of the radius treated by skeletal transfixation in plaster cast: an endresult study of thirty-three cases. J Bone Joint Surg $[\mathrm{Am}]$ 1966; 48-A: $931-45$.

Conney WP III, Linscheid RL, Dobyns JH. External pin fixation for unstable Colles' fractures. J Bone Joint Surg [Am] 1979; 61-A:840-5.

DePalma AF. Comminuted fractures of the distal end of the radius treated by ulnar pinning. J Bone Joint Surg $[\mathrm{Am}]$ 1952: 34-A:651-62.

Dowling JJ, Sawyer B Jr. Comminuted Colles' fractures: evaluation of a method of treatment. J Bone Joint Surg [Am] 1961; 43-A :657-68.

Forgon M, Mammel E. The external fixateur in the management of unstable Colles' fracture. Int Orthop (SICOT) 1981;5:9-14.

Frykman G. Fracture of the distal radius including sequalae-shoulderhand-finger syndrome, disturbance in the distal radio-ulnar joint and impairment of nerve function: a clinical and experimental study. Acta Orthop Scand 1967:Suppl 108.

Gartland JJ Jr, Werley CW. Evaluation of healed Colles' fractures. J Bone Joint Surg [Am] 1951;33-A:895-907.

Grana WA, Kopta JA. The Roger Anderson device in the treatment of fractures of the distal end of the radius. J Bone Joint Surg $[\mathrm{Am}]$ 1979;61-A: 1234-8

Green DP. Pins and plaster treatment of comminuted fractures of the distal end of the radius. J Bone Joint Surg $[\mathrm{Am}]$ 1975: 57-A: 304-10.

Lidström A. Fractures of the distal end of the radius: a clinical and statistical study of end results. Acta Orthop Scand 1959;Suppl 41.

Lucas GL, Sachtjen KM. An analysis of hand function in patients with Colles' fracture treated by rush rod fixation. Clin Orthop 1981; 155: 172-9.

MacFarlane JA, Thomas RH. Fixed skeletal traction in treatment of certain fractures at the wrist. Can Med Assoc J 1937;36:10-2.

Marsh HO, Teal SW. Treatment of comminuted fractures of the distal radius with self-contained skeletal traction. Am J Surg 1972, 124:715-9.

Munson GO, Gainor BJ. Percutaneous pinning of distal radius fractures. J Trauma $1981 ; 21: 1032-5$.

Rush LV, Rush HL. Longitudinal pin fixation on Colles' fracture of the wrist. South Surg 1949;15:679-86.

Sarmiento A, Pratt GW, Berry NC, Sinclair WF. Colles' fractures: functional bracing in supination. J Bone Joint Surg [Am] 1975; 57-A:311-7

Scheck M. Long-term follow-up of treatment of comminuted fractures of the distal end of the radius by transfixation with Kirschner wires and cast. J Bone Joint Surg [Am] 1962:44-A:337-51.

van der Linden W, Ericson R. Colles' fracture: how should its displacement be measured and how should it be immobilized. $J$ Bone Joint Surg $[\mathrm{Am}] 1981 ; 63-\mathbf{A}: 1285-8$. 